Short Paper

\title{
Cone Cells Appear also in the Retina of Eel Larvae
}

\author{
Yuri Omura, ${ }^{* 1, \dagger}$ Kazumasa Uematsu, ${ }^{* 2}$ Hiroyuki Tachiki, ${ }^{* 3}$ \\ Kiyoshi Furukawa, ${ }^{* 4}$ and Hideo Satoh ${ }^{* 4}$ \\ ${ }^{*}$ School of Agricultural Sciences, Nagoya University, Nagoya 464-01, Japan \\ ${ }^{*}$ Faculty of Applied Biological Science, Hiroshima University, \\ Higashi-hiroshima 739, Japan \\ ${ }^{*}$ Aichi Prefectural Fisheries Experimental Station, Hazu-Isshiki 444-04, Japan \\ ${ }^{*}$ Faculty of Agriculture, The University of Tokyo, Tokyo 113, Japan \\ (Received February 28, 1997)
}

Key words: eel Anguilla japonica, leptocephalus, larvae, retina, cone cells, development

Fish larvae of many species, such as salmon, trout, herring, pilchard, left eye flounder, plaice, sole, haddock, perch, goby, stickleback, etc., showed a pure-cone retina with no rods. ${ }^{1-5)}$ In contrast, the retina of the leptocephalus of the European eel Anguilla anguilla showed a homogenous pattern of rod-like photoreceptors similar to those of the adult deep sea fish. ${ }^{1,2)}$ Since this finding, it has been presumed that the retina of the eel leptocephalus may be an exceptional case of pure-rod retina. Usually rod photoreceptors appear first only at metamorphosis and contribute especially to movement perception. ${ }^{\text {) }}$

It may now be possible to obtain cultivated larvae of most fish species, since aquaculture techniques have been well established. Following extraordinary attempts, it has been also established that the larvae of the Japanese eel $A n$ guilla japonica can be produced through the artificial induction of maturation and spawning in aquaria. ${ }^{6-8)} \mathrm{Com}-$ pared to the leaf-like leptocephli collected from the ocean, the cultivated larvae may provide a distinct background of their age and/or birth date.

We obtained the retina of the natural eel leptocephali $(11.0,12.3,21.3 \mathrm{~mm})$, collected at $50-100 \mathrm{~m}$ depth near the North Equatorial Current, west of the Mariana Islands, ${ }^{9)}$ and of the artificial eel larvae (3-7 days after hatching), cultivated in Aichi Prefectural Fisheries Experimental Station or the Fisheries Laboratory of the University of Tokyo. After fixation with $10 \%$ neutral formalin or $2 \%$ glutaraldehyde - $2 \%$ paraformaldehyde - $0.1 \mathrm{M}$ cacodylate buffer, the specimens were embedded in Epon 812, through ethanol dehydration and QY-1 infiltration. Semithin sections $(0.5-1.0 \mu \mathrm{m})$ for light microscopy and ultrathin sections for electron microscopy were made with glass knives and stained in Toluidin Blue and Lead-Uranium, respectively.

In the $11.0 \mathrm{~mm}$-long leptocephlus, surprisingly, the vertical section of the whole eye through the central point close to the optic nerve showed that the central retina contains short (ca. $10 \mu \mathrm{m}$ ) cone-like photoreceptors and the peripheral retina is composed of longer (ca. $40 \mu \mathrm{m}$ ) rodlike photoreceptors (Fig. 1A). In addition, the very similar features as those of the $11.0 \mathrm{~mm}$-long leptocephalus were found in the retinae of cultivated larvae of 7 days after hatching (Fig. 1B). In contrast, the retina of the $12.3 \mathrm{~mm}$ long leptocephalus indicated all rod-like photoreceptors, although the central retina was still somewhat shorter than the peripheral one. The retina of the $21.3 \mathrm{~mm}$-long lep- tocephalus showed a homogenous pattern of longer rodlike photoreceptors.

Electron microscopic features of the rod-like photoreceptor cells revealed the outer segment lamellae to be free from the plasma membrane, while the cone-like photoreceptor cells from the $11.0 \mathrm{~mm}$-long leptocephlus possessed inconspicuous continuity of the lamellae with the plasma membrane. Moreover, the photoreceptor outer segments of 7 days-old cultivated larvae indicated the distinct continuity of the lamellae with the plasma membrane both at the central and the peripheral retina (Figs. 2A, B, C). In the outer plexiform layer of these retinae, most of photoreceptor synaptic terminals seemed to be cone pedicles, containing plural triads with synaptic ribbons (Fig. 2D).

As mentioned above, it is well-known that cone-like photoreceptor cells are dominant in the retina of larval fish, while rod-like cells appear only after or at metamorphosis. So far, it has been considered that pure-rod retina of the eel leptocephalus is an exceptional case of photoreceptor development. In the present study, we found that the retina of larval eel possesses regular cone-like photoreceptor cells at least during the early stage of their development, as those of other pelagic fish larvae.

According to the microanalysis of otolith daily increments, ${ }^{9,10}$ ) the age of the present specimens collected from the ocean are thought to be as follows: $11.0 \mathrm{~mm}$ : ca. 2

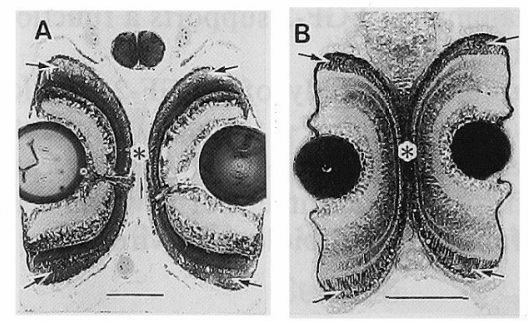

Fig. 1. Comparison of the eel retinae between the natural leptocephalus (11.0 mm long) from the Pacific Ocean (A) and the cultivated larva (7 days-old) from the aquarium (B).

Both the vertical sections through the central region seem to be similar. The central retina (asterisk) contains short cone-like photoreceptors (cf. Fig. 2A), while the peripheral retina (arrows) consists of longer rod-like ones. Each scale indicates $100 \mu \mathrm{m} . \times 90$ (A), $\times 130$ (D).

\footnotetext{
${ }^{\dagger}$ Correspondence to: Laboratory of Animal Information Biology, School of Agricultural Sciences, Nagoya University, Chikusa, Nagoya 464-01, Japan.
} 


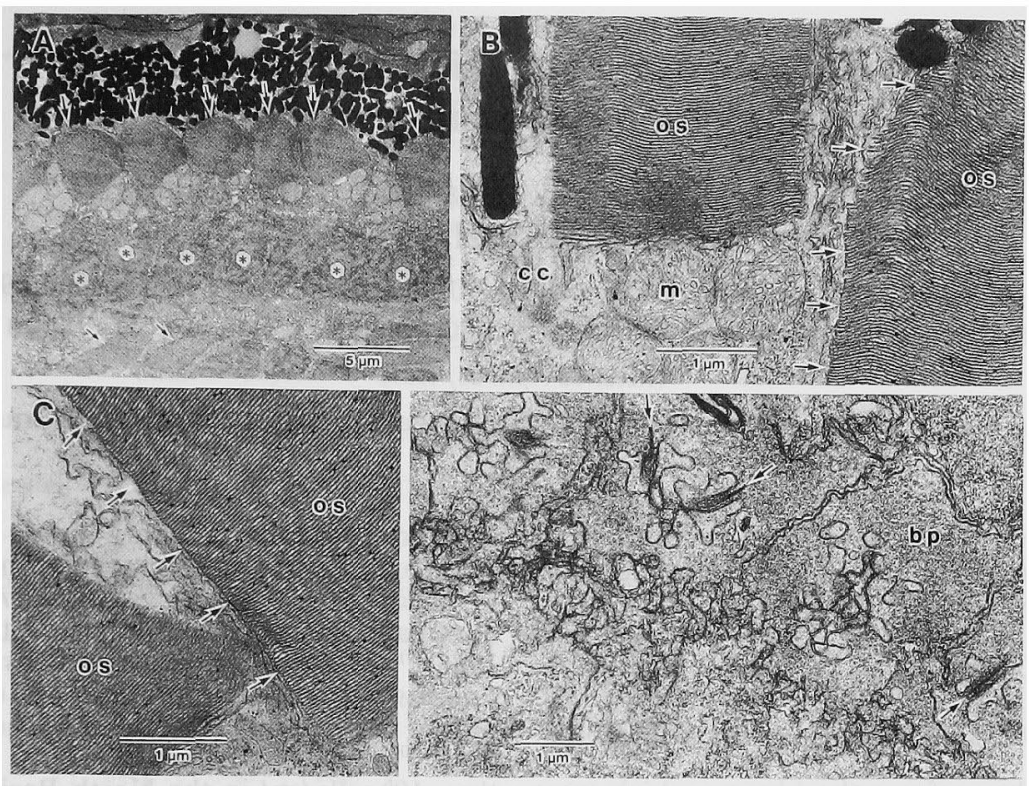

Fig. 2. Electron micrographs of the central (A, B) and peripheral (C, D) retina from the 7 days-old larva.

A. Typical cone-like outer segments (large arrows) are lined up in the central retina. $B$ and $C$. The continuity of the lamellar membrane with the plasma membrane is indicated by arrows. D. Part of the outer plexiform layer including synaptic terminals (bp) of cone-like photoreceptors. Each photoreceptor terminal contains plural synaptic sites with synaptic ribbons (arrows). cc connecting cilium, $\mathrm{m}$ mitochondria, os outer segment. Asterisks and small arrows indicate the nuclei of the photoreceptor and horizontal cells, respectively. $\times 3,100(\mathrm{~A}), \times 16,500(\mathrm{~B}), \times 17,200(\mathrm{C})$, $\times 12,700(\mathrm{D})$.

wks, $12.3 \mathrm{~mm}$ : ca. 3 wks, $21.3 \mathrm{~mm}$ : ca. 5 wks after hatching. In contrast, the specimens of the European eel leptocephali, which indicated single rod-like retina, were 80 $\mathrm{mm}^{1,2)}$ and $50 \mathrm{~mm}^{11)}$ long. It is known that the European eel leptocephali drift on the Gulf Stream and the North Atlantic Current, reaching the Continental Shelf 3 years later after hatching in the Sargasso Sea. ${ }^{2)}$

Compared to the present larvae of the Japanese eel, the much older leptocephali of the European eel were examined in previous reports. ${ }^{1,2,11)}$ Accordingly, we may suggest that also in the retina of the eel, cone-like photoreceptors develop first and rod-like cells appear later. This pattern of photoreceptor development has been generally accepted. ${ }^{13)}$

In addition, we found that the peripheral retina is composed of longer rod-like photoreceptors even in the youngest specimens (11.0 mm long) collected from the ocean. Compared to the other species, rod-like photoreceptors may develop much faster in the eel retina, due to adaptation to their deep and dark habitat. It is considered that rod vision is generally more active in the peripheral retina and is especially involved in movement perception."

The origin of the rod photoreceptors has been controversial: 1) from the germinal zone at the margin, ${ }^{14)}$ or 2 ) within the inner or outer nuclear layer throughout the retina. ${ }^{15,16)}$ In the larval eel, it still remains to be verified whether the rod-like photoreceptors are transformed simply from the cone-like ones during development. Recently, in situ hybridization of the retinal opsin in the goldfish has revealed that the precocious rods express opsin prior to cone opsin expression, but the morphological features of the early-differentiating rods are unknown. ${ }^{17}$

Based on the topograhic differences in cone density of the adult fish retina, usually the area lateralis (or so-called fovea centralis in human retina) has the highest density of cones, providing the visual axis. ${ }^{18,19)}$ Despite the temporal appearance, the pure cone-like arrangement of the central retina of the larval eel may be useful in improving the vi- sion because there is evidence of feeding and ingesting rotifers, Brachionus rotundiformis, in the larval eel cultivated in aquarium, ${ }^{20}$ ) although it is generally considered that visual acuity is very poor in the prelarval fish. ${ }^{1)}$

We thank Prof. K. Tsukamoto, The University of Tokyo, for discussion and Prof. K. Yamauchi, Hokkaido University, for advice.

\section{References}

1) J. H. S. Blaxter: in Vision in Fishes (ed. Ali, M. A.), Plenum, New York, 1975, pp. 427-443.

2) J. H. S. Blaxter and M. J. Staines: Mar. Biol. Assoc. U.K., 50, 449 460 (1970).

3) M. A. Ali: Can. J. Zool., 37, 965-996 (1959).

4) G. Kawamura: in Early Development in Fishes (ed. M. Tanaka) Kouseisha-Kouserikaku, Tokyo, 1991, pp. 9-20.

5) Y. Omura and M. Oguri: Cell Tissue Res., 266, 315-323 (1991).

6) K. Yamamoto and K. Yamauchi: Nature, 251, 220-222 (1974).

7) K. Yamauchi, M. Nakamura, H. Takahashi, and K. Takano: Nature, 263, 412 (1976).

8) H. Satoh: Iden, 33, 23-30 (1979) (in Japanese).

9) K. Tsukamoto: Nature, 356, 789-791 (1992).

10) K. Tsukamoto, A. Umezawa, and T. Ozawa: Nippon Suisan Gakkaishi, 58, 457-459 (1992).

11) N. W. Pankhurst: Can. J. Zool., 62, 335-343 (1984).

12) F. R. Harden Jones: Fish Migration, Edward Arnold, London, 1968.

13) S. E. G. Nilsson: J. Ultrastruct. Res., 11, 581-620 (1964).

14) P. R. Johns: J. Comp. Neur., 176, 343-358 (1977).

15) J. H. S. Blaxter and M. P. Jones: J. Mar. Biol. Ass. U.K., 47, 677697 (1967).

16) P. R. Johns and R. D. Fernald: Nature, 293, 141-142 (1981).

17) D. L. Stenkamp, O. Hisatomi, L. K. Barthel, F. Tokunaga, and P. A. Raymond: Invest. Ophtalmol. Vis. Sci. 37, 363-376 (1996).

18) T. Tamura: Nippon Suisan Gakkaishi, 22, 536-557 (1957).

19) T. Tamura and W. J. Wisby: Bull. Marine Sci. Gulf Caribbean. 13, 433-448 (1963).

20) H. Tanaka, H. Kagawa, H. Ohta, K. Okuzawa, and K. Hirose: Fish eries Sci., 61, 171-172 (1995) 